\title{
A Cognitive Perspective on Knowledge How: Why Intellectualism Is Neuro-Psychologically Implausible
}

\author{
Andreas Stephens ${ }^{1, *}$ and Cathrine V. Felix ${ }^{1,2, *}$ \\ 1 Department of Philosophy, Lund University, 22100 Lund, Sweden \\ 2 Department of Philosophy and Religious Studies, Norwegian University of Science and Technology, \\ 2815 Gjøvik, Norway \\ * Correspondence: andreas.stephens@fil.lu.se (A.S.); cathrine.felix@ntnu.no (C.V.F.)
}

Received: 25 July 2020; Accepted: 24 August 2020; Published: 5 September 2020

\begin{abstract}
We defend two theses: (1) Knowledge how and knowledge that are two distinct forms of knowledge, and; (2) Stanley-style intellectualism is neuro-psychologically implausible. Our naturalistic argument for the distinction between knowledge how and knowledge that is based on a consideration of the nature of slips and basic activities. We further argue that Stanley's brand of intellectualism has certain ontological consequences that go against modern cognitive neuroscience and psychology. We tie up our line of thought by showing that input from cognitive neuroscience and psychology, on multiple levels of analysis, cohere in supporting the distinction between two separate forms of knowledge. The upshot is a neuro-psychologically plausible understanding of knowledge.
\end{abstract}

Keywords: intellectualism; anti-intellectualism; knowledge; knowledge how; knowledge that; naturalism; slips; basic activities

\section{Introduction}

Knowledge is commonly seen as consisting of two forms. The knowledge how to do something, such as riding a bike, and the knowledge that something is the case, such as that Reykjavík is the capital of Iceland. ${ }^{1}$ Ryle [1,2] set an enduring and influential modern debate in motion by discussing the relation between the two forms. According to intellectualism, which Ryle opposes, knowledge how is a form of knowledge that. According to anti-intellectualism on the other hand, which Ryle supports, knowledge how involves abilities and dispositions, and is thereby not a form of knowledge that (see, e.g., [1-3]):

Cleverness at fighting is exhibited in the giving and parrying of blows, not in the acceptance or rejection of propositions about blows ... [n]or does the surgeon's skill function in his tongue uttering medical truths but only in his hands making the correct movements. [2] (p. 48).

Stanley and Williamson [3-5] offers a thought-provoking intellectualist account of knowledge, where they - against Ryle-argue that knowing-how is a form of propositional knowing-that. We will focus on Stanley's [3] formulation, where he presents an intellectualist account arguing that facts are true propositions and that knowledge of how to do things is knowledge of facts:

$[\mathrm{K}]$ nowing how to do something is the same as knowing a fact. It follows that learning how to do something is learning a fact. For example, when you learned how to swim, what happened

1 The distinction is standard in the literature and we will use it throughout the article. However, there are, of course, other conceptualizations of knowledge including, for example, knowledge by acquaintance, as well as knowing which, who, what, what it is like etc. 
is that you learned some facts about swimming. Knowledge of these facts is what gave you knowledge of how to swim. Something similar occurred with every other activity that you now know how to do, such as riding a bicycle or cooking a meal. You know how to perform activities solely in virtue of your knowledge of facts about those activities. [3] (p. vii).

As Schwartz and Drayson [6] point out, it is crucial to make one's own stance in the intellectualist/anti-intellectualist debate clear since a lot of confusion arguably stems from theoreticians talking past each other depending on whether their focus is on semantics or science. In philosophy, numerous different approaches for investigating knowledge have been discussed and promoted, however, the most common focus has been on the concept knowledge, and Stanley's argument centers on a semantic approach. This said, he explicitly discusses cognitive scientific evidence and claims that it supports his position [3,7]. Therefore, this approach is motivated to assess Stanley's claim using a naturalistic approach where the natural phenomenon knowledge, such as science presents it, is seen as being of primary interest. ${ }^{2}$ Our approach is thus cooperative, and complementarily evolutionary, naturalistic in the sense that we consider it essential to take empirical evidence and scientific theories into account-trumping intuitions-when such input is available in order to find a plausible account of knowledge. All philosophical questions are then legitimate, although their answer will need to be compatible with scientific input [8-14].

There have been a number of naturalistic attacks on Stanley's position (see, e.g., [15-17]), yet while we largely agree with most of these arguments, we want to add a pluralistic perspective that highlights consideration of the nature of slips and basic activities as well as the scientific multi-level coherence for the case against intellectualism.

In short, we claim that the intellectualist position of knowledge how is untenable in light of relevant scientific theorizing and evidence. In defense of our view, we put forth and defend the following two theses: (1) knowledge how and knowledge that should be seen as two distinct forms of knowledge, and (2) intellectualism is neuroscientifically and psychologically implausible.

\section{Stanley's Intellectualism}

We will follow Stanley [3] in focusing on procedural knowledge how and propositional knowledge that, although both phenomena can be, and have been, conceptualized along, for example, the following lines concerning knowledge and memory: tacit/implicit versus explicit; non-declarative/procedural versus declarative; practical versus theoretical. These various pairs involve subtle differences in connotation. However, it is often hard to pinpoint the exact usage in debates where the various concepts tend to be used interchangeably. However, given our naturalistic approach, this is somewhat less problematic since it, in our view, is ultimately the natural world that governs how the natural phenomenon knowledge should be understood.

Stanley claims that a reluctance to accept the intellectualist view often depends on an incorrect understanding of what knowledge of facts amounts to, i.e., not properly accounting for the connection between knowledge of facts and action. It is, according to Stanley, special kinds of facts-propositions answering the relevant "how-questions" - that enables knowledge how. Stanley points out that:

Humans are thinkers and humans are agents. There is a natural temptation to view these as distinct capacities, governed by distinct cognitive states. When we engage in reflection, we

2 While most naturalists acknowledge the natural world as being "all-encompassing," and science as providing our best method of understanding it, there are a number of different interpretations of where this leaves philosophy [8]. An ontological naturalism that rejects anything supernatural is commonly accepted although there is still debate whether, for example, the mental can be reduced to the physical [9]. However, the proper form of methodological naturalism is a much debated issue, involving positions which argue for replacing epistemology with cognitive psychology [10], substantially reformulating philosophical problems into scientific terminology [11], or for cooperatively taking scientific input into account whenever such information is available [12]. Moreover, evolutionary naturalism has highlighted how cognitive agents are shaped by natural selection-information which might replace, succeed or complement epistemology $[13,14]$. 
are guided by our knowledge of propositions. By contrast, when we engage in intelligent action, we are guided by our knowledge of how to perform various actions. If these are distinct cognitive capacities, then knowing how to perform an action is not a species of propositional knowledge. [3] (p. 1, italics in original).

As we will show below, it is actually the case that engaging in reflection and intelligent action does involve distinctly different cognitive capacities, which means that intellectualism will be hard to defend.

Stanley positions himself against Ryle [1,2], but what he formulates is first and foremost an empirical question. Therefore, we will look to cognitive psychology and cognitive neuroscience as the most relevant sources of input and answers. Stanley does discuss how cognitive scientific evidence ought to inform philosophy, but his interpretation is problematic for reasons we will discuss below. In short, we claim that a general problem with Stanley's approach is that it conflates the possibility of describing an agent performing an action with an agent actually being able to perform that action (see, e.g., [17], Section 4).

Stanley does qualify his position and wants to separate knowledge how from involving ability, and argues that "knowing how to do something does not entail being able to do it" [3] (p. 127). This is, however, not a satisfactory position. Indeed, it is correct that, for example, a pianist, in a sense, might know how to play the piano even after losing their arms. However, contrary to Stanley, this would be due to neural pathways that have been entrained by numerous hours spent behind the keys, not due to propositional facts that the pianist "thinks of practically". They might be able to describe how someone else ought to go about it to play a certain tune, but unless that person, in turn, actually put in the work to get similar relevant neural pathways that person would be unable to actually play, and therefore not know how to play (see, e.g., [18]). In addition, since Stanley [3] (p. 131) explicitly claims that his "view of the nature of knowing how to do something is a view about the metaphysical nature of these states, and not a view in semantics" we believe that it involves several problematic features.

Stanley's focus on language and questioning of the relevance of scientific input is problematic from a naturalistic perspective like the one we defend. He discusses the matter thus:

Why would one expect it to be a virtue of an account of knowing how that it is plausibly taken to be what is expressed by ascriptions of knowing how in natural language? Shouldn't we be open to the possibility that science could show us that states of knowing how are very different in kind from what ordinary speakers use sentences like "Ana knows how to swim" to express? If so, then although it might be a virtue of an account of the meaning of ascriptions of knowing how that it is plausibly correct for natural language, it is not a virtue of an account of the nature of states of knowing how. And it is the latter that concerns the philosopher, and not the former. In various forms and versions, this is the foundational objection to the methodology I have employed. [3] (pp. 143-144).

Stanley [3] (p. 144, italics in original) concludes that "[i]t could hardly be that science could discover that knowing how to swim was a distinct state than is expressed by 'knowing how to swim'. After all, quite minimal principles governing the nature of the truth-predicate render this incoherent."

However, this is non-naturalistic argumentation that seems to rely completely on a certain set of intuitions as a foundation. To let the intuitive usage of language dictate-and overrule - in advance, what science conceives of as a natural phenomenon is a radical position that Stanley does not present convincing support for. Importantly, he at other places wants to use cognitive scientific input in defense of his position, which we will get back to below (see, e.g., [3] (ch. 7), [7]). His initial commitment to view facts as propositions seems to have led him astray. It is possibly this position that renders Stanley unaccommodating towards Noë's [16] critique of his (and Williamson's) focus on language, ascriptions of knowledge, and a semantic understanding of propositionality (see also, e.g., [19]), rather than the nature of the mind and knowledge seen as a natural phenomenon [3] (p. 146). It seems to be this 
interpretation, where cognitive science only can amount to different understandings of "relations between propositions" [3] (p. 148), that makes Stanley evade the conclusion from the scientific theories he himself quotes ([20] (p. 209), [21] (pp. 562-563), see also [6,16,17]); knowing how and knowing that are actually different phenomena that involve different cognitive processes, and the two forms of knowledge are explicitly held apart by science (see, e.g., [20,22-25], see also [16,26]).

Stanley [3] (p. 150) claims that "knowing how to do something is a kind of propositional knowledge, a kind of propositional knowledge that guides skilled actions." He argues that this is the case by claiming that declarative knowledge is but one form of propositional knowledge; procedural (non-declarative) knowledge can also be propositional, or so Stanley argues. In order to make this account fit better with scientific evidence, he goes on to highlight that not all propositional knowledge needs to be capable of being verbalized ${ }^{3}$ and that knowing how to do something is conceptual. It is prima facie reasonable to assume that an intellectualist of Stanley's disposition would defend the view that knowledge how includes an ability to verbalize the knowledge in question (see also footnote 3). However, it is sufficient on Stanley's account that the agent in question can make use of demonstrative expressions like "this", exemplified by Stanley thorough the imagined case of the young Mozart who, when asked how he is composing his music merely points to one of his masterpieces and says "this is how I can do it" (emphasise is ours). In another paper ("A Naturalistic Perspective on Knowledge How: Grasping Truths in a Practical Way" [28]), we argue that one would expect from an intellectualist account like Stanley's, that the agent can express their knowledge how in a more illuminating sense than by the mere use of demonstrative expressions. Stanley, however, simply states that if one accepts that all words count, then demonstrative expressions should be accepted as ways of expressing one's knowledge how [4] (p. 214). In fact, Stanley argues that words are not needed at all to demonstrate knowledge how. He tries to show this through the example of an expert boxer who fights a southpaw. By boxing the exact way he does, the expert proves through his agency that he knows how to fight a southpaw. He does not need to say how he knows or what he does when fighting, because he is, as a matter of fact doing it, due to skill, not mere luck. As we write in our paper, we find this approach unsatisfactory given the overall intellectualist framework Stanley defends.

With some caution, we can concede that not all propositional knowledge needs to be capable of being verbalized. Importantly, though, this hinges on exactly how one interprets a number of factors, such as, for example, how knowledge is connected to various forms of long-term memory, and their correlating neurological substrate, among other issues. For example, depending on how one draws the line concerning propositional knowledge and its connection to episodic and/or semantic long-term memory, different interpretations come out as being most plausible.

Stanley introduces an interesting point when he writes that the distinction between procedural and propositional knowledge does not involve two forms of states but rather two ways of generating or implementing a particular state of knowledge [3] (p. 151). This is a possible interpretation, but should ultimately be evaluated with a focus on the actual underlying cognitive phenomena (processes). By merely focusing on very high-level aspects of knowledge Stanley seems to be drawn to biologically implausible conclusions. This is, for example, salient when he in a footnote writes that "[b]eing merely procedurally implemented cannot be sufficient for knowing how" [3] (p. 153, fn. 2, italics in original). Simple mechanical processes, on this account, are then not enough for knowledge how. However, this point is debatable. Many organisms, for example, have simple reflexive mechanisms that enable them to interact with their environment in a way that, arguably, ought to be viewed as involving knowing how to do something — a point we will get back to below (see, e.g., $[29,30]$ ).

3 Stanley [4] (p. 213) quotes Fodor [27] (p. 634): “There is a real and important distinction between knowing how to do a thing and knowing how to explain to do that thing. But that distinction is one that the intellectualist is perfectly able to honor ... The ability to give explanation is itself a skill—a special kind of knowing how which presupposes general verbal facility at the very least. But what has this to do with the relation between knowing how and knowing that? And what is there here to distress an intellectualist?". 
The view we defend can be developed further to include animal cognition, for example along the lines developed by Jan Faye's evolutionary naturalist approach [30]. However, we will not discuss the topic in detail in this paper. It is a project for another paper. Some details regarding Stanley's account should be mentioned though. In a brief passage in his book Know How [3] (p. 133), Stanley discusses Alva Noë's critique that Stanley and Williamson [5], given their intellectualism, are forced to say that animals can grasp propositions because animals obviously knows how to do many things, a dog, for example, knows how to catch a frisbee. The point is not that animals cannot grasp propositions, but rather that this is a highly controversial issue. Stanley's reply seems to dodge the critique. His reply is, in short, that automaticity of action and animal cognition fits all varieties of knowing-wh (where, when, whether etc.). Stanley remarks that a philosophical account of knowledge how that says that it is not a kind of propositional knowledge will have the unlucky result that many cases of knowing-wh too do not ascribe propositional knowledge [3] (p 134). Does Stanley bite the bullet, or not? Given what he says, it is hard to tell.

\section{Basic Activities and Slips}

Basic activities are of special interest to our enquiry. Basic activities are those activities we automatically know how to perform; we pull them off by doing nothing else. They are the very source of agency, the material of which all other actions are made. As such they are a necessary condition for all other matters connected to agency. When someone performs basic activities, they do so by making bodily movements that constitute the fundamental atoms of what they are attempting to accomplish, grounding every other action. They do so without any need to determine the means by which the action should be performed. Basic activities are such that the agent knows how to perform them, say, "just like that." Consider the example from Hornsby of someone saying "grass is green" [31]. The utterance is performed through movements of the tongue, mouth, teeth, etc. The agent does not make these movements because they believe that they are a means of saying "grass is green"; they probably have no particular beliefs about them and are hardly aware of them. They do not do them intentionally in the way they intentionally utters the sentence as a whole. From the agent's perspective, basic activities have a teleological structure, and one can perform them without any need to understand their details correctly. On such a teleological view, basic activities are relative to the agent: acts that are basic for one agent may not be for another. Moreover, something that is basic for an agent in one setting may not be in another. Consider the agent for whom using their own hot-water kettle is a basic action while using a hot-water kettle of unfamiliar design is not.

The possibility of slips is of special interest to the naturalistic view we defend. Slips-performances one can successfully do while intending something else-genuinely reveal what one can do in a basic sense, "just like that", precisely because one has all the necessary bodily skills to perform them. Because of that capacity, one can reasonably be expected to be able to perform them intentionally as well. A basic activity is one the agent can perform even while making a slip. We think those things that one is able to do even while making a slip are the ones that truly are basic. In other words, "slipping behavior" reveals basicness. A slip is the kind of performance that would often, in another context, be meaningfully intended. After all, slips are not random. Verbal slips show lexical biases, tend to result in grammatically correct utterances, and rarely violate the syntactic constraints of the language; so Fromkin [32] (p. 183) writes: "according to all linguists who have analyzed spontaneous speech errors, the errors are nonrandom and predictable". This is important, because it illuminates how an agent's knowledge how is operative when they slip. When an agent slips by grasping the salt instead of the sugar, then this is not because they are incompetent in distinguishing salt from sugar. What the slip shows is misdirected competence. Slips are small episodes of misdirected behavior in otherwise correctly performed action sequences, often closely resembling the correct act. Salt is not so far from sugar in terms of appearance or use. Contrast the act of grasping the salt instead of the sugar with that of accidentally taking a handful of soil from a pot of tulips: such action surely would be baffling, 
because it differs so much from what is expected. The point becomes particularly clear with so-called slips of the tongue: the agent who slips speaks comprehensible words, not mere nonsense.

To specify even more, slips are executive failures; you go left instead of right, you pour milk instead of water, you push the button marked " 1 " instead of the one marked " 2 " etc. In the case of a slip, the agent bluntly does something different from what they mean to be doing. The failure is not at a cognitive level, thus the agent does not fail because they have a false belief and the like [33-36]. Crucially, the agent slips despite knowing that their performance is an error. The agent who is about to add milk to their coffee, but pours juice instead does not err because they cannot tell the difference between milk and juice: clearly, they can. Competence does not provide immunity from slips: the person who slips does not do so because they lack the relevant ability. They are fully able to grab, lift, and pour from a container; they just happen to grab the wrong one. They slip not because their movements are beyond their control, like those made by someone suffering from a compulsive disorder or Anarchic Hand syndrome, ${ }^{4}$ but because, then and there, they simply make the wrong movements. Among other things, an important thing to notice here is that the agent has the correct propositional content and is normally able to apply it, but, for some reason, their knowledge that and their knowledge how came apart and they acted in some sense successfully: they performed actions that belong to their basic action repertoire (they pull them off "just like that") - -i.e., they poured milk instead of juice, they did not start singing into the jug or jump up and down—on a different propositional content than they meant to act on. How can knowledge that and -how come apart like this if knowledge how is merely a species of the former? The topic of basicness in general and the above discussed split between knowledge how and knowledge that in particular is not discussed by Stanley. He does not consider the basicness of activities the way we do. Instead of focusing on basicness, he focuses on knowledge of truths and is ignorant towards executive mistakes in the sense we are interested in here, it just is not among his concerns. He states that when you learn some truths about swimming, then you know how to swim and after the acquisition of that fact it seems, on his intellectualist account, that you can, of course, do something wrong when swimming, boxing and cycling, but, crucially, you cannot bluntly apply the wrong content and be wrong about how you should swim or cycle. When you have learned how to swim, you simply know. In other words, when you have gained the knowledge of swimming, you cannot "unknow" it, in the same way as after the moment you genuinely learned the truths about how to walk, you cannot be wrong about walking, to walk is something you know how to do. One of our points is that Stanley's account can make one lose sight of neuro-psychological facts like the simple point that human beings sometimes slip and in the slip, knowledge how and knowledge that come apart, as we have shown in the above examples. The failure to see this is one of the things that we find biologically misconceived in the intellectualist account. This is, in a nutshell, our critique: slips show how knowledge how has epistemic properties not present in knowledge that. When an agent slips, they do something different from what they intended; nonetheless, the performance is guided by their knowledge how. This reveals a divide between the knowledge that actively guides behavior: the knowledge how that the agent applies sub-consciously; and the knowledge how they intend to guide their behavior in the first place, which they are under the illusion of acting on even as they slips. We argue that this divide between two levels of knowledge how operative in the slip case has no parallel when it comes to knowledge that. Therefore, knowledge how cannot be reduced to knowledge that. As we will explain in further detail below, a reason for why slips occur can be a slip-up in the communication between different cognitive processes in the mind of the agent at the time of acting.

4 Addressing Anarchic Hand syndrome, Marcel [37] (p. 77) writes: “the affected hand performs unintended but complex, well-executed, goal-directed actions. Often when the patient is trying to do something with the unaffected hand, the other hand appears to do the opposite or compete with it." 


\section{Grounding Knowledge}

By looking to cognitive psychology and cognitive neuroscience we can gain a lot of insight regarding the cognitive underpinnings of knowledge (see, e.g., [38-45]). In particular, we will argue that various influential theories focusing on different levels of analysis provide a multi-level coherent picture. From a first high-level perspective, dual process theory offers elucidating input for our discussion. According to this influential theory, ${ }^{5}$ cognitive processes consist in Type 1 processes (System 1) and Type 2 processes (System 2). Type 1 processes are fast, reflexive, and non-conscious, whereas Type 2 processes are slow, reflective, and conscious. These different processes are plausibly mapped to different forms of knowledge. In short, knowledge how can plausibly be tentatively mapped to reflexive Type 1 processes and knowledge that can plausibly be tentatively mapped to reflective Type 2 processes (see, e.g., [46,47], see also [48]):

Motor behavior, moreover, can take place without the experience of intentional states or reasoning, not only in the case of true reflexes but also, importantly, in the case of expert performance, such as that of an athlete "in the zone" or a chess master. [49] (p. 34)

On a lower level of analysis, the human memory systems follow the same pattern (see, e.g., [20,43-45]. Tulving's account states that long-term memory consists in three parts working together-procedural, semantic, and episodic memory-where " ... procedural memory entails semantic memory as a specialized subcategory, and ... semantic memory, in turn, entails episodic memory as a specialized subcategory." [43] (pp. 2-3). Type 1 processes can plausibly be mapped to procedural memory involving bottom-up action schemas, abilities, and skills that are possible to learn through trial and error. Type 2 processes can plausibly be mapped to episodic memory involving propositional, factual remembrance, and the experienced first-person point of view. As an intertwined intermediate, semantic memory involves conceptual content and categorization. Using Cohen and Squire's ([20], see also [22]) canonical conceptualization, this division can be classified as non-declarative (or procedural) versus declarative memory:

Declarative memory includes what can be declared or brought to mind as a proposition or an image. ... Non-declarative memory refers to a heterogeneous collection of abilities: motor skills, perceptual skills, and cognitive skills (these abilities and perhaps others are examples of procedural memory); as well as simple classical conditioning, adaptation/eve/effects, pdming, and other instances where experience alters performance independently of providing a basis for the conscious recollection of past events. [22] (p. 171)

On yet a lower level of analysis, procedural memory involves, for example, the basal ganglia, neocortex, cerebellum, striatum, and the premotor- and primary motor cortex (see, e.g., [50]). Semantic memory involves, for example, associative pathways, the prefrontal cortex, the lateral-, ventral- and medial temporal cortex, basal ganglia, and hippocampus (see, e.g., [50]). Episodic memory involves, for example, attentional pathways, the prefrontal, ventral fronto-temporal, medial temporal, retrosplenial, and posterior cingulate cortices, the parahippocampal, angular, middle temporal, the fusiform, and inferior temporal gyrus, as well as the left posterior insula and the hippocampus (see, e.g., [50]).

To use motor output as an example, thoughts, intentions, and knowledge that involve Type 2 processes, episodic memory, the frontal lobe and cortex, and varying layers of smaller and larger homotypical cells. Associations and conceptual knowledge involve semantic memory, the parietal lobe and association cortex, and varying layers of smaller and larger homotypical cells. Whereas knowledge how involves Type 1 processes, procedural memory, the primary motor cortex, cerebellum, and large

5 We are aware of critical voices (see, e.g., [38,42], see also the discussion below). 
agranular cells (see, e.g., [50]). Investigations on multiple levels of analysis, and from different scientific perspectives, thus support a division of knowledge how and knowledge that.

Now, this understanding of memory and knowledge has recently been criticized by De Brigard [51] -although his focus is specifically on the non-declarative (procedural)/declarative view of the memory systems, which he calls the standard model of memory (SMM). We consider many of his points interesting and meriting further investigation that might ultimately lead to a new interpretation of the memory systems. However, note that the SMM account differs in certain details from Tulving's account which we have presented above. We therefore believe that De Brigard's critique loses a lot of its bite when this is taken into consideration. Regarding the intellectualist position specifically, we do consider De Brigard's arguments to be underwhelming since he presents a very dogmatic interpretation of what he dubs the "empirical argument." On his interpretation, this line of reasoning demands that "P2. Knowledge how is equivalent to (or, at least, exclusively depends on) procedural [non-declarative] memory, whereas knowledge that is equivalent to (or, at least, exclusively depends on) declarative memory." [51] (p. 728). We believe this premise to be a misleading interpretation and would change the phrasings "equivalence" and "exclusive dependence" to something less strong and domineering. For the anti-intellectualist argument, formulations in the line of that "knowledge how is primarily based in (and primarily depends on) procedural memory" would suffice. This is enough to counter the intellectualist position. Importantly, we also question De Brigard's [51] (p. 728) third premise "P3. But the scientific evidence captured by the SMM demonstrates that procedural (non-declarative) and declarative memory are two entirely dissociable and independent systems." As we have briefly described above, Tulving's account of memory posits that long-term memory involves procedural, semantic, and episodic memory, and that the three systems work in parallel. However, importantly, procedural memory is evolutionarily prior to semantic and episodic memory which means that if any reduction is to be made, it ought to go the complete opposite way from how intellectualists see things (see, e.g., [52,53]).

Stanley [3] argues that because episodic and semantic memory are separate forms of declarative memory and knowledge, not all declarative knowledge is propositional (only semantic memory and knowledge is). This is a reasonable, albeit not undisputed, interpretation. However, it does not follow that procedural memory and knowledge should be viewed as being propositional. By gaining propositional knowledge it is possible to gain in skill, but only after using this propositional knowledge to actually perform actions repeatedly. Stanley's (see, e.g., [3], pp. 155-159) characterization of this process vastly downplays the reflexive and unconscious processes involved in acquiring procedural knowledge and vastly exaggerates the role of propositional knowledge in skillful actions. Stanley argues for his interpretation, where (explicit) procedural knowledge should be viewed as propositional, but does not present empirical evidence supporting this interpretation. He rather bases it on his discussions of how people ascribe knowledge how to others. However, empirical evidence instead indicates the non-propositional nature of procedural memory and knowledge, where "[d]eclarative or explicit knowledge is available to consciousness, and can readily be expressed verbally, whereas procedural or implicit knowledge is typically unconscious and can only be expressed verbally with some difficulty and sometimes not at all" ([23], p. 65; see, e.g., [20,23-25], see also, e.g., [6,16,17,26]). Devitt [16] sums up the situation as follows:

Despite disagreement or uncertainty on many other issues, psychologists speak with one voice on this one. Even production-system theories, which seem to posit representations of processing rules and hence seem to have the most "intellectualized" picture of procedural knowledge, distinguish this knowledge sharply from declarative knowledge. Psychology presents a picture of procedural knowledge as constituted somehow or other by embodied, probably unrepresented rules that are inaccessible to consciousness. It is thus quite different from declarative knowledge which consists of representations that are available to consciousness. ... In sum, a nonpropositional view of knowledge how is not just 
philosophical prejudice or even just folk theory: it seems to be entrenched in psychology and cognitive ethology. [16] (pp. 213-215)

In other words, procedural (non-declarative) processes do not involve brain regions and processes linked to language in the same way as declarative memory and knowledge do. Stanley's semantic reading and idiosyncratic stipulation of what procedural and propositional knowledge involves thus runs against empirical evidence and scientific theorizing, and mischaracterizes the number of non-conscious processes involved in procedural knowledge how (see, e.g., [6] (Section 4.2), [15] (p. 287), [17] (Section 2)).

Devitt [16] argues for claims that are similar to those we have presented, pointing out that it is problematic to base one's view of knowledge solely on linguistic arguments ${ }^{6}$ concerning ascriptions of knowledge. Devitt [16] (p. 206) further argues that knowledge how does not reduce to knowledge that, but does temper his claim to state that "... perhaps one kind of knowledge how is knowledge that. But I still want to maintain that another kind is not. There is a common kind of knowledge how that a person can have simply on the basis of having the ability to perform an activity." It would then be wrong to claim that all knowledge how reduces to knowledge that.

We are sympathetic to Devitt's view, but maybe he gives too much slack to the intellectualist position? After all, all knowledge how involves vast amounts of non-conscious processes (see, e.g., [24,55]:

There is now considerable evidence to suggest that the performance of reward-related actions in both rats and humans reflects the interaction of two quite different learning processes, one controlling the acquisition of goal-directed actions, and the other the acquisition of habits. This evidence suggests that, in the goal-directed case, action selection is governed by an association between the response 'representation' and the 'representation' of the outcome engendered by those actions, whereas in the case of habit learning, action selection is controlled through learned stimulus-response (S-R) associations without any associative link to the outcome of those actions. As such, actions under goal-directed control are performed with regard to their consequences, whereas those under habitual control are more reflexive in nature, by virtue of their control by antecedent stimuli rather than their consequences. [56] (p. 49)

The intellectualist thus ignores empirical evidence and scientific theorizing, and is thus, at its core, a problematic methodology (see, e.g., [57]).

It is clear that knowledge how for Stanley is substantially tied to language use. Even though it is not a requirement that the agent in question is able to express in words their knowledge how, it is required that they, in some sense, are both a language-user and have a concept of self. This is so because having knowledge how for Stanley amounts to knowing the answer to a question, and moreover, to apply the acquired knowledge to oneself (realizing that I can $\Phi$ ). In sum, it seems that Stanley must hold that the concepts of language and self are necessarily involved in having knowledge how. This, by comparison, is not a demand on our view since knowledge how on our account basically rests on procedural memory (see Section 4). The claim that knowing how to do something is conceptual is, or so we argue, potentially problematic or even false. We do believe that the bulk of (cognitive) scientific input strongly indicates that animals are capable of conceptualizing their environment, while not being capable of language, and that Stanley's position is deeply problematic. As we point out, regardless of how one draws the line concerning declarative memory (semantic and/or episodic LTM), it does not

6 Stanley and Williamson ([5], p. 441) write that their account follows "from basic facts about the syntax and semantics of ascriptions of knowledge how". It springs from a theory of embedded questions: according to which knowing how is treated as on a par with knowing whether, knowing when and so on. We do not offer an extensive analysis of Stanley's linguistic arguments here. Our view, in short, sides with Glick's [54] view, saying that using mere linguistic premises, about knowledge how ascriptions, to support substantive conclusions about the nature of knowledge how just cannot do the job it is supposed to do. 
follow that non-declarative memory (procedural LTM), which is most reasonably tied to knowledge how, or so we argue in the paper, is conceptional, and even less so; propositional. In sum, we hold the view that verbalization is not necessary for conceptualization. Moreover, we hold that there are plausible arguments to be had for both positions, but that we want to leave the question open to further debate. Importantly, however, we argue that it is up to Stanley to prove that non-propositional knowledge how is reasonable to tie to propositional knowledge that-which we argue that he does not succeed with. In other words, it strikes us that the burden of proof is on Stanley, where we consider his account to be idiosyncratic and not in line with a naturalistic interpretation of relevant scientific input.

\section{Grounding Slips}

Recall the phenomenon of slips. The cognitive processes underlying knowledge how and knowledge that, and how they come apart, can be elucidated by this phenomenon:

The 'slips of action' that punctuate daily life illustrate that our behaviour is not always goal-directed in nature. Folk wisdom suggests that such slips of action occur when well-practised responses intrude to compromise our goal-directed behaviour. For example, it is a common-place experience to find oneself arriving at the door of the old office although one's original intention was to get to the new one. Adams [58] was the first to show that in rats extensive training of the instrumental response of lever pressing rendered it impervious to devaluation of the food outcome, a finding that has now been replicated in a number of rodent studies. [59] (p. 471).

Goal-directed control of actions is important to ensure that one's behavior has the desired result. However, experiments by de Wit et al. [60] show that such control competes with habitual responses. In dual process terminology; reflective Type 2 processes can be "hijacked" by reflexive Type 1 processes, which results in slips of action. Importantly, de Wit et al. point out that a reason for such slips can be that although Type 2 processes allow for greater flexibility, Type 1 processes demand less cognitive effort. Loosely speaking, the system (agent) might thus automatically fall back into default mode in order to save energy. If this is done incorrectly the agent slips. Empirical studies ${ }^{7}$ suggest that dopamine plays a central role in regulating the interplay between the cognitive processes regarding this matter, and how slips occur (see, e.g., $[60,61])^{8}$

Rasmussen [62] (see also [48], p. 43) offers a three-level model that classifies human behavior as being either skill-based, rule-based, or knowledge-based. Skill-based behavior consists in non-conscious automatic actions demanding extensive training. Rule-based behavior, on an intermediate level, consists in actions guided by information acquired empirically or through communicated instructions. Knowledge-based behavior consists in goal-controlled actions that do not rely on know how or rules but rather are based on reflective cognitive processes.

Focusing on knowledge how, Rasmussen's account can be interpreted as presenting an olive branch towards Stanley's [3] and Stanley and Williamson's [5] accounts in that knowledge how might plausibly be seen as consisting in both a procedural element (procedural memory) and a rule-based element (semantic memory):

In general, the skill-based performance rolls along without the person's conscious attention, and he will be unable to describe how he controls and on what information he bases the performance. The higher level rule-based coordination is generally based on explicit know how, and rules used can be reported by the person. [62] (p. 259)

Where Stanley and Williamson go wrong is that they ignore the procedural element and only focus on the rule-based element. Moreover, they ascribe features more suitably linked to knowledge-based

7 Studies have primarily been done on animals, but those that focus on humans indicate that generalizability is plausible.

8 This said, for example, serotonin is also thought to play an important role. 
behavior to knowledge how, and finally claim that it is possible to reduce knowledge how to knowledge that which is completely unsubstantiated.

Representing actions with schemas, Norman $(1981)^{9}$ develops a similar account:

A major assumption of the ATS [activation-trigger-schema] theory for slips is that skilled actions-actions whose components are themselves all highly skilled-need only be specified at the highest levels of their memory representations. Once the highest-level schema is activated, the lower-level parent components of that action sequence complete the action, to a large extent autonomously, without further need for intervention except at critical choice points. [36] (p. 4)

Mismatches from episodic memory (false beliefs) can, arguably, be seen as involving knowledge that. This is so since formations of intentions involve reflective features that we have argued above is linked to episodic long-term memory and working memory. These types of mismatches can usually be fixed by focused attention and additional cognitive energy expenditure. Slips due to mismatches from procedural memory are more readily seen to involve knowledge how, where a particular action schema is executed-but not the intended one. In these cases, we are thus in possession of relevant knowledge how, but we accidentally carry out some other knowledge how (schema) that we also possess.

\section{The Neuro-Psychological Implausibility of Intellectualism}

Humans are but one animal among others. It is therefore essential to take animal cognition research into account when investigating knowledge how and knowledge that. As we have argued above, knowledge can be seen to be grounded in the memory systems. An important point regarding this topic is that procedural memory (linked to knowledge how) is evolutionarily prior to semantic and episodic memory (linked to knowledge that).

Accordingly, many animals are capable of knowledge how without having a language, and thus arguably not having knowledge that. Once again, if there is a reduction to be made, it should therefore reduce knowledge that to knowledge how rather than the other way around (see, e.g., [52,53]).

Now, Stanley and Krakauer [7] try to wedge knowledge how apart by focusing on skilled actions, where they argue that motor skill demands propositional knowledge that of facts whereas motor acuity ("precision of selected actions") does not. Contrary to canonical cognitive scientific interpretations keeping propositional knowledge and skill apart, Stanley and Krakauer [7] (p. 1) argue that "... learning to become skilled at a motor task, for example tennis, depends also on knowledge-based selection of the right actions[,]" and then go on to argue that "... skilled activity requires both acuity and knowledge, with both increasing with practice." We concede that Stanley and Krakauer have a point in that knowledge that indeed might increase acuity, but that it only can do so to a comparatively very limited—indeed infinitesimally small—amount. It is therefore, in our view, misleading to push this detail in the manner Stanley and Krakauer do. Stanley and Krakauer even go further and promote an idiosyncratic view, that appears contrary to well-established interpretations in cognitive psychology and cognitive neuroscience, in claiming that "the identification of procedural knowledge, itself a misnomer, with the colloquial understanding of motor skill ... [and] the identification of declarative knowledge with knowledge in the traditional sense [are incorrect]" [7] (p. 2):

Does the fact that manifesting skill requires knowledge preclude non-human animals from possessing skills? We are agnostic as to whether animals can be skilled. It is possible that as a task is weighted increasingly toward rules, alternative actions, and on-the-fly problem

9 According to Norman [36], slips in the form of intentional formational errors involve cases where a specific action schema is intended but vagueness and contextual factors intervene. Slips, in the form of faulty activations, involves actions that result from unintended schemas that might be similar to or associated with the intended schema, or are due to the loss of activation. Slips, in the form of faulty triggerings, can result both from failures to trigger schemas or by triggering at inappropriate circumstances. 
solving, then simple operant conditioning may not suffice to accomplish the task. In this sense non-human animals may be limited in a way similar to the amnestic patients in the Roy and Park experiment. Although non-human animals may exhibit the same behavior as humans, this does not entail that the explanation for the behavior is the same. It could be that the explanation skilled action in humans involves intellectual capacities lacking in non-human animals.... Alternatively, it could be that animals can both possess concepts and bear the knowledge relation to propositions (if so, one would need to explain why animals cannot acquire certain skills that humans can; perhaps because there complex skills require complex concepts, which cannot be grasped by animals). [7] (p. 9)

As Noë highlights, abilities are embodied and situated in ways that are deeply problematic for intellectualism [15] (p. 284), and contrary to the intellectualist position, we have shown that procedural knowledge how is a distinct form of knowledge from propositional knowledge that, involving separate brain areas, cognitive processes, and cell-types (see, e.g., [56]), and these findings are generalizable across species:

Rodent studies have implicated prelimbic cortex and its striatal efferents on dorsomedial striatum as a key circuit responsible for goal-directed learning. In a series of fMRI studies, vmPFC has been found to be involved in encoding reward predictions based on goal-directed action-outcome associations in humans, suggesting that this region of cortex in the primate prefrontal cortex is a likely functional homolog of prelimbic cortex in the rat. Furthermore, the area of anterior caudate nucleus found in humans to be modulated by contingency would seem to be a candidate homolog for the region of dorsomedial striatum implicated in goal-directed control in the rat. Finally, the evidence reviewed here supports the suggestion that a region of dorsolateral striatum in rodents and of the putamen in humans is involved in the habitual control of behavior, which when taken together with the findings on goal-directed learning reviewed previously, provides converging evidence that the neural substrates of these two systems for behavioral control are relatively conserved across mammalian species. [56] (p. 54).

\section{Concluding Remarks}

The gist of the present article has been to make a case for a more plausible understanding of knowledge. An understanding of knowledge that, to some extent, harmonizes with agents' subjective experience of their actions when it comes to such phenomena as slips and basic actions, but primarily in regards to cognitive psychological and neuroscientific findings on the nature of agency. This has led us to argue for a distinction between knowledge how and knowledge that, and against a Stanley-styled intellectualism. Our argument against the latter has been that Stanley's position has certain ontological consequences that do not equate well with neuroscience and psychology. Moreover, cognitive sciences support a distinction between knowledge how and knowledge that; a distinction that especially comes to the fore, we have argued, in the phenomenon of slips.

Author Contributions: Both authors have contributed to: Conceptualization, Methodology and Writing-Original draft preparation, Review and Editing. All authors have read and agreed to the published version of the manuscript.

Funding: A.S. gratefully acknowledges support from Makarna Ingeniör Lars Henrik Fornanders fond and Stiftelsen Elisabeth Rausings minnesfond: forskning.

Acknowledgments: We thank our anonymous reviewers for valuable comments.

Conflicts of Interest: The authors declare no conflict of interest.

\section{References}

1. Ryle, G. Knowing how and knowing that. Proc. Aristot. Soc. 1946, 46, 1-16. [CrossRef]

2. Ryle, G. The Concept of Mind; University of Chicago Press: Chicago, IL, USA, 1949. 
3. Stanley, J. Know How; Oxford University Press: Oxford, UK, 2011.

4. Stanley, J. Knowing (how). Noûs 2011, 45, 207-238. [CrossRef]

5. Stanley, J.; Williamson, T. Knowing how. J. Philos. 2001, 98, 411-444. [CrossRef]

6. Schwartz, A.; Drayson, Z. Intellectualism and the argument from cognitive science. Philos. Psychol. 2019, 32, 661-691. [CrossRef]

7. Stanley, J.; Krakauer, J.W. Motor skill depends on knowledge of facts. Front. Hum. Neurosci. 2013, 7, 1-11. [CrossRef] [PubMed]

8. Rysiew, P. Naturalism in epistemology. In The Stanford Encyclopedia of Philosophy, 2017th ed.; Zalta, E.N., Ed.; CSLI: Stanford, CA, USA, 2017; Available online: https://plato.stanford.edu/archives/spr2017/entries/ epistemology-naturalized (accessed on 25 August 2020).

9. Stoljar, D. Physicalism. In The Stanford Encyclopedia of Philosophy, 2017th ed.; Zalta, E.N., Ed.; CSLI: Stanford, CA, USA, 2017; Available online: https://plato.stanford.edu/archives/win2017/entries/physicalism/ (accessed on 25 August 2020).

10. Quine, W.V.O. Epistemology naturalized. In Ontological Relativity and Other Essays; Columbia University Press: New York, NY, USA, 1969; pp. 69-90.

11. Churchland, P.S. Mind-brain reduction: New light from the philosophy of science. Neuroscience 1982, 7 , 1041-1047. [CrossRef]

12. Kornblith, H. Knowledge and its Place in Nature; Oxford University Press: Oxford, UK, 2002.

13. Campbell, D.T. Evolutionary epistemology. In The Philosophy of Karl R. Popper; Schilpp, P.A., Ed.; Open Court: LaSalle, IL, USA, 1974; pp. 412-463.

14. Bradie, M.; Harms, W. Evolutionary epistemology. In The Stanford Encyclopedia of Philosophy, 2017th ed.; Zalta, E.N., Ed.; CSLI: Stanford, CA, USA, 2017; Available online: https:/plato.stanford.edu/archives/spr2017/ entries/epistemology-evolutionary (accessed on 25 August 2020).

15. Noë, A. Against intellectualism. Analysis 2005, 65, 278-290. [CrossRef]

16. Devitt, M. Methodology and the nature of knowing how. J. Philos. 2011, 108, 205-218. [CrossRef]

17. Roth, M.; Cummins, R. Intellectualism as cognitive science. In Knowledge and Representation; Newen, A., Bartels, A., Jung, E.-M., Eds.; CSLI: Stanford, CA, USA, 2011; pp. 23-39.

18. Fridland, E. Knowing-how: Problems and considerations. Eur. J. Philos. 2015, 23, 703-727. [CrossRef]

19. Glauer, R. The semantic reading of propositionality and its relation to cognitive-representational explanations: A commentary on Andreas Bartels and Mark May. In Open MIND: 2(C); Metzinger, T., Windt, J.M., Eds.; MIND Group: Frankfurt am Main, Germany, 2015.

20. Cohen, N.; Squire, L. Preserved learning and retention of pattern-analyzing skill in amnesia: Dissociation of knowing how and knowing that. Science 1980, 210, 207-210. [CrossRef]

21. Tardif, T.; Wellman, H.M.; Fung, K.Y.F.; Liu, D.; Fang, F. Preschoolers' understanding of knowing-that and knowing-how in the United States and Hong Kong. Dev. Psychol. 2005, 41, 562-573. [CrossRef] [PubMed]

22. Squire, L.R.; Zola-Morgan, S. Memory: Brain systems and behavior. Trends Neurosci. 1988, 11, $170-175$. [CrossRef]

23. Annett, J. On knowing how to do things: A theory of motor imagery. Cogn. Brain Res. 1995, 3, 65-69. [CrossRef]

24. Aarts, H.; Dijksterhuis, A. Habits as knowledge structures: Automaticity in goal-directed behavior. J. Personal. Soc. Psychol. 2000, 78, 53-63. [CrossRef]

25. Anderson, J.R. Cognitive Psychology and its Implications, 7th ed.; Worth Publishers: New York, NY, USA, 2009.

26. Wallis, C. Consciousness, context, and know how. Synthese 2008, 160, 123-153. [CrossRef]

27. Fodor, J. The appeal to tacit knowledge in psychological explanation. J. Philos. 1968, 65, 627-640. [CrossRef]

28. Felix, C.V.; Stephens, A. A Naturalistic Perspective on Knowledge How: Grasping Truths in a Practical Way. Philosophies 2020, 5, 5. [CrossRef]

29. Shettleworth, S.J. Cognition, Evolution, and Behavior; Oxford University Press: Oxford, UK, 2010.

30. Faye, J. The Nature of Scientific Thinking. On Interpretation, Explanation and Understanding; Palgrave Macmillan: London, UK, 2014.

31. Hornsby, J. Actions; Routledge \& Kegan Paul: London, UK, 1980.

32. Fromkin, V.Slips of the Tongue. Sci. Am. 1973, 181-187. Available online: http://web.stanford.edu/ \{\}zwicky/ slips-of-the-tongue.pdf (accessed on 24 June 2015). [CrossRef]

33. Amaya, S. Slips. Nôus 2013, 47, 559-576. [CrossRef] 
34. Anscombe, G.E.M. Intention; Harvard University Press: Harvard, IL, USA, 2000.

35. Baars, B.J. The many uses of error: Twelve steps to a unified framework. In Experimental Slips and Human Error: Exploring the Architecture of Volition; Baars, B.J., Ed.; Plenum Press: New York, NY, USA, 1992; pp. 3-38.

36. Norman, D.A. Categorization of action slips. Psychol. Rev. 1981, 88, 1-15. [CrossRef]

37. Marcel, A. The sense of agency: Awareness and ownership of action. In Agency and Self-Awareness: Issues in Philosophy and Psychology; Roessler, J., Eilan, N., Eds.; Oxford University Press: Oxford, UK, 2003; pp. 48-93.

38. Gigerenzer, G.; Regier, T. How do we tell an association from a rule? Comment on Sloman. Psychol. Bull. 1996, 119, 23-26. [CrossRef]

39. Keren, G.; Schul, Y. Two is not always better than one: A critical evaluation of two-system theories. Perspect. Psychol. Sci. 2009, 4, 533-550. [CrossRef] [PubMed]

40. Kruglanski, A.W.; Chun, W.Y.; Erb, H.P.; Pierro, A.; Mannett, L.; Spiegel, S. A parametric unimodel of human judgment: Integrating dual-process frameworks in social cognition from a single-mode perspective. In Social Judgments: Implicit and Explicit Processes; Forgas, J.P., Williams, K.R., von Hippel, W., Eds.; Cambridge University Press: New York, NY, USA, 2003; pp. 137-161.

41. Kruglanski, A.W.; Gigerenzer, G. Intuitive and deliberative judgements are based on common principles. Psychol. Rev. 2011, 118, 97-109. [CrossRef]

42. Barrett, H.C. The Shape of Thought: How Mental Adaptations Evolve; Oxford University Press: Oxford, UK, 2015.

43. Tulving, E. Memory and consciousness. Can. Psychol. 1985, 26, 1-12. [CrossRef]

44. Tulving, E. Episodic memory: From mind to brain. Annu. Rev. Psychol. 2002, 53, 1-25. [CrossRef] [PubMed]

45. Baddeley, A.D. Working Memory, Thought and Action; Oxford University Press: Oxford, UK, 2007.

46. Evans, J.S.B.T.; Stanovich, K.E. Dual-process theories of higher cognition: Advancing the debate. Perspect. Psychol. Sci. 2013, 8, 223-241. [CrossRef] [PubMed]

47. Lizardo, O.; Mowry, R.; Sepulvado, B.; Stoltz, D.S.; Taylor, M.A.; Van Ness, J.; Wood, M. What are dual process models? Implications for cultural analysis in sociology. Sociol. Theory 2016, 34, 287-310. [CrossRef]

48. Reason, J. Human Error; Cambridge University Press: Cambridge, UK, 1990.

49. Horst, S. Cognitive Pluralism; MIT Press: Cambridge, MA, USA, 2016.

50. Kandel, E.R.; Schwartz, J.H.; Jessell, T.M.; Siegelbaum, S.A.; Hudspeth, A.J. (Eds.) Principles of Neural Science, 5th ed.; McGraw-Hill, Health Professions Division: New York, NY, USA, 2013.

51. De Brigard, F. Know how, intellectualism, and memory systems. Philos. Psychol. 2019, 32, 720-759. [CrossRef]

52. Hetherington, S. Knowing-that, knowing-how, and knowing philosophically. Grazer Philos. Stud. 2008, 77, 307-324. [CrossRef]

53. Hetherington, S. How to Know: A Practicalist Conception of Knowledge; John Wiley \& Sons: West Sussex, UK, 2011.

54. Glick, E. Two methodologies for evaluating intellectualism. Philos. Phenomenol. Res. 2011, 83, 398-434. [CrossRef]

55. Bargh, J.A. Goal $\neq$ intent: Goal-directed thought and behavior are often unintentional. Psychol. Inq. 1990, 1, 248-251. [CrossRef]

56. Balleine, B.W.; O'Doherty, J.P. Human and rodent homologies in action control: Corticostriatal determinants of goal-directed and habitual action. Neuropsychopharmacology 2010, 35, 48-69. [CrossRef] [PubMed]

57. Cath, Y. Knowing how. Analysis 2019, 79, 487-503. [CrossRef]

58. Adams, C.D. Variations in the sensitivity of instrumental responding to reinforcer devaluation. Q. J. Exp. Psychol. Sect. B 1982, 34B, 77-98. [CrossRef]

59. De Wit, S.; Dickinson, A. Associative theories of goal-directed behaviour: A case for animal-human translational models. Psychol. Res. PRPF 2009, 73, 463-476. [CrossRef] [PubMed]

60. De Wit, S.; Standing, H.R.; DeVito, E.E.; Robinson, O.J.; Ridderinkhof, K.R.; Robbins, T.W.; Sahakian, B.J. Reliance on habits at the expense of goal-directed control following dopamine precursor depletion. Psychopharmacology 2012, 219, 621-631. [CrossRef]

61. Nelson, A.; Killcross, S. Amphetamine exposure enhances habit formation. J. Neurosci. 2006, 26, 3805-3812. [CrossRef]

62. Rasmussen, J. Skills, rules, and knowledge: Signals, signs, and symbols, and other distinctions in human performance models. IEEE Trans. Syst. Man Cybern. 1983, 13, 257-266. [CrossRef]

(C) 2020 by the authors. Licensee MDPI, Basel, Switzerland. This article is an open access article distributed under the terms and conditions of the Creative Commons Attribution (CC BY) license (http://creativecommons.org/licenses/by/4.0/). 